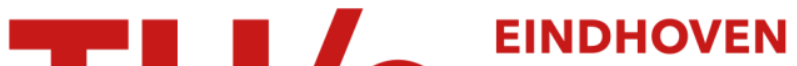 UNIVERSITY OF TECHNOLOGY
}

\section{Visualisation of trip chaining behaviour and mode choice using household travel survey data}

\section{Citation for published version (APA):}

Wallner, G., Kriglstein, S., Chung, E., \& Kashfi, S. A. (2018). Visualisation of trip chaining behaviour and mode choice using household travel survey data. Public Transport, 10(3), 427-453. https://doi.org/10.1007/s12469018-0183-5

DOI:

10.1007/s12469-018-0183-5

Document status and date:

Published: 01/12/2018

\section{Document Version:}

Accepted manuscript including changes made at the peer-review stage

\section{Please check the document version of this publication:}

- A submitted manuscript is the version of the article upon submission and before peer-review. There can be important differences between the submitted version and the official published version of record. People interested in the research are advised to contact the author for the final version of the publication, or visit the $\mathrm{DOI}$ to the publisher's website.

- The final author version and the galley proof are versions of the publication after peer review.

- The final published version features the final layout of the paper including the volume, issue and page numbers.

Link to publication

\section{General rights}

Copyright and moral rights for the publications made accessible in the public portal are retained by the authors and/or other copyright owners and it is a condition of accessing publications that users recognise and abide by the legal requirements associated with these rights.

- Users may download and print one copy of any publication from the public portal for the purpose of private study or research.

- You may not further distribute the material or use it for any profit-making activity or commercial gain

- You may freely distribute the URL identifying the publication in the public portal.

If the publication is distributed under the terms of Article $25 \mathrm{fa}$ of the Dutch Copyright Act, indicated by the "Taverne" license above, please follow below link for the End User Agreement:

www.tue.nl/taverne

Take down policy

If you believe that this document breaches copyright please contact us at:

openaccess@tue.nl

providing details and we will investigate your claim. 


\title{
Visualisation of trip chaining behaviour and mode choice using household travel survey data
}

\begin{abstract}
Planning for transport infrastructure requires forecasting of future travel demand. Various factors such as future population, employment, and the travel behaviour of the residents drive travel demand. In order to better understand human travel behaviour, household travel surveys - which require participants to record all their trips made during a single day or over a whole week - are conducted. However, the daily travel routines of people can be very complex, including routes with multiple stops and/or different purposes and often may involve different modes of transport. Visualisations that are currently employed in transport planning are, however, limited for the analysis of complex trip chains and multi-modal travel. In this paper, we introduce a unique visualisation approach which simultaneously represents several important factors involved in analysing trip chaining: number and type of stops, the quantity of traffic between them, and the utilised modes of transport. Moreover, our proposed technique facilitates the inspection of the sequential relation between incoming and outgoing traffic at stops. Using data from the South-East Queensland Travel Survey 2009, we put our developed algorithm into practice and visualise the journey to work travel behaviour of the residents of inner Brisbane, Australia. Our visualisation technique can assist transport planners to better understand the characteristics of the trip data and, in turn, inform subsequent statistical analysis and the development of travel demand models.
\end{abstract}

JEL Codes: R29, R41 \& R42

Keywords: Trip chain; Multi-modal travel; Trip scheduling; Human travel behaviour; Visualisation; Household Travel Survey. 


\section{Introduction}

Effective transport planning is crucial for building modern, productive, and environmentally sustainable cities and regions. Therefore, understanding the travel activities of the population is of particular importance as it helps to guide the planning of transport infrastructure and services in order to make our communities better places to live. Visualisation techniques used in the field of transportation planning aim to represent the complex nature of human travel activities. They are a means to facilitate and clarify the understanding of multifaceted information in relation to transportation. Transportation visualisation, according to Manore (2007), can be defined as "any progressive visual means of representing static or temporal spatial and geometric information". In the context of transport planning, visualisation techniques are an important aspect not only for analysing data (e.g., by means of Geographic Information Systems - GIS) but also for clearly conveying the outcomes of transportation planning to policy makers or the general public. Lately, visualisations in transportation are also increasingly employed in interactive public transport journey planners such as the journey planner of London (Transport for London), the Public Transport Victoria journey planner (Public Transport Victoria), the Rail travel planner Europe (Rail Europe - Rail travel planner Europe), or the TransLink Journey planner Brisbane (TransLink Journey Planner) to name but a few examples.

While individual trips have long served as the basic unit for analysing travel behaviour, there has been a shift of focus to journeys - so-called trip chains - as those are deemed to better reflect the actual travel demands (Ma et al. 2014). Trip chaining arises for several reasons including the desire of people to search for ways to perform multiple activities in a single journey within less time and travel distance (Shiftan 1998; Hensher and Reyes 2000). Trip chaining behaviour constitutes a complex phenomenon influenced by a variety of variables (McGuckin and Murakami 1999; Ma et al. 2014) such as household characteristics. This is further complicated by the fact that the individual trips themselves can be complex and often involve different or multiple modes of transport. Islam and Habib (2012) state that trip chaining and mode choice are two critical factors influencing various patterns of urban travel demand. In many instances increasing the complexity of trip chains leads to higher auto dependency (Strathman et al. 1994; Wallace et al. 2000; Ye et al. 2007) and to spreading the urban peak periods (Ye et al. 2007; Habib et al. 2009). Generally, trip chaining is prevalent among workers in urban areas. Analysis of trip chains so far has mainly concentrated on the home-to-work commute (McGuckin and Murakami 1999; Primerano et al. 2008). The mandatory work journey serves as an important anchor in many households around which the daily travel activity is scheduled (Hensher and Reyes 2000; Xianyu 2013). Most of the previous Journey to Work (JTW) studies applied statistical analysis to understand the proportions and types of trip chains (e.g., McGuckin and Murakami 1999; Primerano et al 2008; Islam and Habib 2012) or to estimate the role of various demographic or socioeconomic characteristics on the daily travel behaviour (e.g., Strathman et al. 1994; Hensher and Reyes 2000; Ma et al. 2014).

Understanding such multi-modal trip chaining through an appropriate visualisation technique has become an increasingly important aspect in transport planning to optimise public transport and 
to contribute to sustainable urban transportation (Fiorenzo-Catalano et al. 2004). However, visualisation techniques currently employed in transport planning mostly focus on depicting the quantity of trips between zones, for example, by means of choropleth or pie chart maps (Corcoran et al. 2009; Xu et al. 2011) or by using desire lines (Xu and Milthorpe 2010). Other visualisations, in turn, focus on the travel between different stations but often restrict themselves to single modes of transport, such as rail or bus travel (Xu et al. 2011; Nagel et al. 2014). Thus, these visualisations are limited for analysing series of trips or multi-modal trips.

The visualisation technique introduced in this paper aims to provide an overview of human travel behaviour and to facilitate the analysis of such multi-modal travel and trip chaining. Its aim is to convey how different activities using different modes of transport are linked together during a trip (or trip chain) in order to reach a destination in a single picture. As a use case we visualise the JTW travel behaviour of residents of inner Brisbane based on Household Travel Survey (HTS) data of South East Queensland (SEQ) from 2009.

The remainder of this paper is structured as follows. After highlighting our research objectives and significance, we provide a detailed literature review of existing studies on trip chaining and multi-modal human travel behaviour and the employed visualisation approaches. Section 3 gives a detailed description of the algorithm and the graphical representation. Section 4 provides a brief description of the study area and the employed data. In Section 4 we also apply the visualisation approach to data from the SEQ Travel Survey 2009 (SEQTS09) and interpret the results. Before the paper is concluded in Section 6, Section 5 discusses implications of the developed visualisation approach in theoretical and practical settings as well as the runtime of the algorithm. Section 5 also explores avenues for future research.

\subsection{Research Objectives}

Our literature review presented in Section 2 suggests that there has been little research on a systematic way of visualising HTS data to provide an overview of the complexity of trip making such as trip chaining and travel mode choice (single or multi-modal). This paper contributes to filling this gap by proposing a visualisation technique that can be used to analyse trip chains, multi-modal travel, or both in combination. To achieve this goal this paper makes the following contributions:

- It provides a review of visualisation techniques currently employed in studies dealing with trip chaining and multi-modal travel behaviour.

- It proposes a new visualisation technique for analysing complex human travel behaviour, specifically trip chaining and multi-modal travel. For this purpose, the visualisation shows several important variables such as frequency of trips, mode choice, as well as the number and succession of stops in a single drawing.

- It demonstrates the applicability of our approach by applying it to real world HTS data from Brisbane, Australia from 2009 to highlight how transport planners and agencies can benefit from it. 


\subsection{Research Significance}

This study aims to make a contribution to the complex task of modelling trip behaviour. Our proposed visualisation can help to unlock stories behind the trip data or present information in an easy to digest manner and, in turn, can aid transport planners in forming hypothesis for subsequent statistical analysis. It can also inform the creation of transport models used in urban studies to forecast travel demand and travel behaviour (Bhat and Koppelman 1999). Commonly used models like agent-based modelling (Monteiro et al. 2014) or tour-based travel demand modelling (Omer et al. 2010) rely on personal trip data. Understanding how trips are performed is therefore essential for building such models.

\section{Literature Review}

This section demonstrates various visualisation methods that were adopted in previous studies concerned with trip chaining and/or travel mode choice (single or multi-modal).

Using 2011 census data on modes of travel to work in England and Wales, Leveson (2013) used bar charts, stacked bar charts, and pie charts to compare different modes of travel and their changing patterns over the years. Adopting a different approach, Xu and Milthorpe (2010) analysed JTW travel patterns in Sydney using data from 1981 to 2006 . Besides using bar charts to compare the share of different modes of travel and line charts to depict the relation between trip length and distance between home and workplace, desire lines were used to visualise the traffic volumes between origin-destination pairs. Taken together, these desire lines can be viewed as a (directed or undirected) weighted graph with the weights representing the traffic volume. Xu et al. (2011), in turn, focused specifically on the analysis of travel patterns of rail users based on data from the Sydney Household Travel Survey. Again, stacked bar and line charts were used for analysing trip lengths. In addition, pie chart maps - pie charts superimposed over a map - were created to visualise the modes of transport used to access the stations (e.g., by bus or on foot). Using Nationwide Personal Transportation Survey data, McGuckin and Murakami (1999) investigated the types of trip chains made by adult men and women. This study made use of bar charts to compare the trip chaining behaviour between men and women on their home-to-work or work-to-home journey with respect to the number and purpose of stops on their trips. Unlike the above studies, which made use of static charts, Nagel et al. (2014) proposed a multi-touch tabletop application to analyse specific aspects pertaining to bus travel in Singapore's bus network. For example, a map representation was used to show the number of alighting and boarding passengers at the different bus stops by means of two concentric circles. In addition, arc diagrams were used to depict the number of passengers travelling between stops to assess passenger flow and connectivity of bus stops. Recently, Sun et al. (2016) discussed visualisation methods for representing aggregated passenger flow characteristics between stations using the Shanghai Metro as a use case. A radial node-link diagram was used to convey the amount of passenger flow between stations. However, unlike our visualisation intermediate stops are not discernable. In general, the studies mentioned above either focus only on a single mode of travel 
or on the utilization of different transport modes whereas our concern is to also facilitate the analysis of multi-modal travel. It shows how different modes of transport are linked together during a trip (or trip chain) to reach a destination.

While above-mentioned studies explored either trip chaining or multi-modal travel behaviour, other studies analysed both (McGuckin et al. 2005; Walle and Steenberghen 2006; Golob and Hensher 2007; Hensher 2007; Ye et al. 2007; Currie and Delbosc 2011; Islam and Habib 2012; Harney and Rajoo 2015). For example, McGuckin et al. (2005) used bar and stacked bar charts to examine the percentage of stops during commutes to comprehend trip chaining trends in the United States. Harney and Rajoo (2015) analysed how intermediate stops, mode choice, and timing of trips differ depending on the tours undertaken in the South East Queensland and Cairns regions. 3D surface plots were used to depict the temporal distributions of the tours. Golob and Hensher (2007) as well as Hensher (2007) used three-year Sydney travel survey data to investigate senior citizens' trip chaining travel activity (either work or non-work centric trips). Line graphs were employed to illustrate the average home-based trip chains based on different demographic attributes such as age, gender, living circumstance, trip purpose, complexity of trips, and mode. Similarly, Ye et al. (2007) examined the relation between mode choice and trip chaining behaviour in the context of multi-stop (complex) vs. single-stop (simple) trips. Their results suggest that the complexity of the trip chaining patterns drives mode choice. Table 1 offers on overview of studies including the various visualisation techniques used to represent data.

Table 1 Previous studies related to trip chaining or multi-modal travel behaviour or both

\begin{tabular}{|c|c|c|c|c|c|}
\hline Author \& year & Study location & Data used & Subject & $\begin{array}{l}\text { Analysis } \\
\text { method }\end{array}$ & $\begin{array}{l}\text { Visualisation } \\
\text { technique(s) }\end{array}$ \\
\hline Leveson (2013) & England \& Wales & $\begin{array}{c}\text { Census Data, } \\
2011\end{array}$ & $\begin{array}{c}\text { Method of travel to } \\
\text { work }\end{array}$ & $\begin{array}{c}\text { Descriptive } \\
\text { statistical analysis }\end{array}$ & $\begin{array}{c}\text { Bar charts, stacked } \\
\text { bar charts, pie } \\
\text { charts, choropleth } \\
\text { maps }\end{array}$ \\
\hline Xu et al. (2011) & Sydney, AU & $\begin{array}{c}\text { Sydney } \\
\text { Household } \\
\text { Travel Survey }\end{array}$ & $\begin{array}{c}\text { Mode share } \\
\text { (single), access } \\
\text { mode to rail station, } \\
\text { trip length }\end{array}$ & $\begin{array}{c}\text { Descriptive } \\
\text { statistical analysis }\end{array}$ & $\begin{array}{l}\text { Bar charts, stacked } \\
\text { bar charts, line } \\
\text { graphs, scatter } \\
\text { plots, tables, pie } \\
\text { chart maps }\end{array}$ \\
\hline $\begin{array}{l}\text { Xu and } \\
\text { Milthorpe } \\
(2010)\end{array}$ & Sydney, AU & $\begin{array}{c}\text { JTW Data } \\
(1981-2006)\end{array}$ & $\begin{array}{l}\text { Mode share (single } \\
\text { or multiple) \& trip } \\
\text { length }\end{array}$ & $\begin{array}{c}\text { Descriptive } \\
\text { statistical analysis }\end{array}$ & $\begin{array}{l}\text { Bar charts, stacked } \\
\text { bar charts, pie } \\
\text { charts, line graphs, } \\
\text { pie chart maps, } \\
\text { desire lines }\end{array}$ \\
\hline $\begin{array}{l}\text { McGuckin et al. } \\
\text { (2005) }\end{array}$ & US & $\begin{array}{c}\text { Nationwide } \\
\text { Personal } \\
\text { Transportation } \\
\text { Survey } 1995 \text { \& } \\
\text { National HTS } \\
2001\end{array}$ & $\begin{array}{l}\text { trip chaining } \\
\text { patterns \& travel } \\
\text { patterns of } \\
\text { commuters }\end{array}$ & $\begin{array}{c}\text { Descriptive } \\
\text { statistical analysis }\end{array}$ & $\begin{array}{l}\text { Bar charts, line } \\
\text { graphs, tables }\end{array}$ \\
\hline $\begin{array}{c}\text { Walle and } \\
\text { Steenberghen } \\
(2006)\end{array}$ & Belgium & $\begin{array}{c}\text { Belgian Mobility } \\
\text { Survey, 1998- } \\
1999\end{array}$ & $\begin{array}{l}\text { Trip chaining \& } \\
\text { mode choice }\end{array}$ & Regression model & $\begin{array}{c}\text { Bar charts, } \\
\text { choropleth maps }\end{array}$ \\
\hline
\end{tabular}




\begin{tabular}{|c|c|c|c|c|c|}
\hline $\begin{array}{l}\text { McGuckin and } \\
\text { Murakami } \\
\text { (1999) }\end{array}$ & US & $\begin{array}{l}\text { Nationwide } \\
\text { Personal } \\
\text { Transportation } \\
\text { Survey, } 1995\end{array}$ & $\begin{array}{l}\text { Trip chaining } \\
\text { behaviour between } \\
\text { men \& women }\end{array}$ & $\begin{array}{c}\text { Descriptive } \\
\text { statistical analysis }\end{array}$ & Bar charts \\
\hline $\begin{array}{c}\text { Currie and } \\
\text { Delbosc (2011) }\end{array}$ & Melbourne, AU & $\begin{array}{c}\text { Melbourne } \\
\text { Household } \\
\text { Travel Survey } \\
\text { Data, 1994- } \\
1999\end{array}$ & $\begin{array}{l}\text { Complexity of trip } \\
\text { chaining behaviour }\end{array}$ & $\begin{array}{c}\text { Statistical } \\
\text { significance } \\
\text { analysis using t- } \\
\text { test }\end{array}$ & Bar charts \\
\hline $\begin{array}{l}\text { Harney and } \\
\text { Rajoo (2015) }\end{array}$ & SEQ \& Cairns, AU & $\begin{array}{l}\text { SEQ and Cairns } \\
\text { Travel Survey }\end{array}$ & $\begin{array}{l}\text { Mode choice, trip } \\
\text { timing, length \& } \\
\text { purpose of stops }\end{array}$ & $\begin{array}{c}\text { Descriptive } \\
\text { statistical analysis }\end{array}$ & $\begin{array}{c}\text { Stacked bar charts, } \\
\text { 3D surface plots, } \\
\text { tables }\end{array}$ \\
\hline Hensher (2007) & Sydney, AU & $\begin{array}{c}\text { Sydney } \\
\text { Household } \\
\text { Travel Survey, } \\
\text { 2002-2004 }\end{array}$ & $\begin{array}{c}\text { Individual trip } \\
\text { chaining travel } \\
\text { activity }\end{array}$ & $\begin{array}{c}\text { Statistical } \\
\text { analysis, nested } \\
\text { logit model }\end{array}$ & Line graphs \\
\hline $\begin{array}{c}\text { Golob and } \\
\text { Hensher (2007) }\end{array}$ & Sydney, AU & $\begin{array}{c}\text { Sydney } \\
\text { Household } \\
\text { Travel Survey, } \\
\text { 2002-2004 }\end{array}$ & $\begin{array}{c}\text { Trip chaining travel } \\
\text { activity }\end{array}$ & $\begin{array}{c}\text { Multiple } \\
\text { correspondence } \\
\text { analysis }\end{array}$ & Line graphs \\
\hline $\begin{array}{c}\text { Alsnih and } \\
\text { Hensher (2005) }\end{array}$ & Sydney, AU & $\begin{array}{c}\text { Sydney } \\
\text { Household } \\
\text { Travel Survey, } \\
2002 \\
\end{array}$ & $\begin{array}{l}\text { Mode of travel, trip } \\
\text { chaining patterns of } \\
\text { aging people }\end{array}$ & $\begin{array}{c}\text { Descriptive } \\
\text { statistical analysis }\end{array}$ & Tables \\
\hline $\begin{array}{c}\text { Islam and } \\
\text { Habib (2012) }\end{array}$ & Switzerland & $\begin{array}{c}\text { Six-Week Travel } \\
\text { Diary Data, } \\
2003\end{array}$ & $\begin{array}{c}\text { Hierarchical trip } \\
\text { chaining \& mode } \\
\text { choice }\end{array}$ & $\begin{array}{c}\text { Structural } \\
\text { equation } \\
\text { modelling (SEM) }\end{array}$ & Tables \\
\hline $\begin{array}{l}\text { Primerano et } \\
\text { al. (2008) }\end{array}$ & Adelaide, AU & $\begin{array}{c}\text { Household } \\
\text { Travel Surveys } \\
\text { Metropolitan } \\
\text { Adelaide, } 1999\end{array}$ & $\begin{array}{l}\text { Trip chaining } \\
\text { behaviour of } \\
\text { households }\end{array}$ & $\begin{array}{c}\text { Descriptive } \\
\text { statistical analysis }\end{array}$ & Tables \\
\hline Xianyu (2013) & Beijing, CN & $\begin{array}{c}\text { Household } \\
\text { Travel Surveys, } \\
2005\end{array}$ & $\begin{array}{l}\text { Trip chaining \& } \\
\text { mode choice of the } \\
\text { home-based work } \\
\text { tour }\end{array}$ & $\begin{array}{l}\text { Co-evolutionary } \\
\text { approach } \\
\text { combining two } \\
\text { multinominal logit } \\
\text { models }\end{array}$ & Tables \\
\hline $\begin{array}{l}\text { Strathman et } \\
\text { al. (1994) }\end{array}$ & Portland, OR, US & $\begin{array}{c}\text { Household } \\
\text { Travel Survey, } \\
1985 \\
\end{array}$ & Trip chaining & Logit model & Tables \\
\hline Ye et al. (2007) & Switzerland & $\begin{array}{c}\text { Swiss } \\
\text { Microcensus } \\
\text { Travel Survey, } \\
2000\end{array}$ & $\begin{array}{c}\text { Mode choice \& } \\
\text { complexity of trip } \\
\text { chaining patterns }\end{array}$ & $\begin{array}{l}\text { Tour-based \& } \\
\text { activity based } \\
\text { travel demand } \\
\text { modelling } \\
\text { systems }\end{array}$ & Tables \\
\hline $\begin{array}{c}\text { Philip et al. } \\
\text { (2013) }\end{array}$ & Kerala, IN & $\begin{array}{c}\text { Interviews } \\
\text { based on } \\
\text { questionnaire }\end{array}$ & $\begin{array}{l}\text { Mode choice } \\
\text { behaviour }\end{array}$ & $\begin{array}{l}\text { Multinominal } \\
\text { logit model }\end{array}$ & Pie charts \\
\hline Ma et al. (2014) & Beijing, CN & $\begin{array}{l}\text { Beijing Activity } \\
\text { Diary Survey } \\
2007 \text { \& Land } \\
\text { Use Data }\end{array}$ & Trip chaining & $\begin{array}{l}\text { Multinominal } \\
\text { logit models }\end{array}$ & $\begin{array}{l}\text { Scatter plots, spider } \\
\text { graphs, choropleth } \\
\text { maps, tables }\end{array}$ \\
\hline
\end{tabular}


As Table 1 shows, most of the studies used either descriptive statistics or advanced statistical techniques to perform their analysis. However, mainly bar charts, pie charts, scatter plots, line graphs, or simple tables were used to visualise data such as the percentage of used travel modes and the stops/number of legs per trip chain, sometimes in combination with the activities at each stop. It also shows that it is uncommon to find visualisation techniques specifically intended for visualising trip-chains (single or complex), activities, and/or mode choice (single or multi) in transportation research. Furthermore, it is rare to find studies that focus on trip chaining and multi-modal travel behaviour simultaneously. Hence, our goal is to facilitate the analysis of multimodal travel, that is, how different modes of transport are linked together during a trip (or trip chain) in order to reach a destination by means of a visualisation technique specifically designed for this purpose.

Apart from the scientific literature reviewed above there are also several tools for visualizing trips. For example, TransCAD (Caliper Corporation) is a transportation planning software, which provides different visualisation methods (e.g., pie chart maps or weighted node-link diagrams superimposed over maps). These can be used to analyse, for instance, trip generation and distribution. The JTW Visualiser (Bureau of Transport Statistics, New South Wales) is an interactive tool for visualising trip flows. In contrast to TransCAD it does not use map-based representations but makes use of a radial graph layout to show the outgoing or incoming traffic between a certain region of interest and other suburbs. When selecting an edge, the utilized modes of travel are depicted next to the graph using bar charts. However, as the bar charts are only displayed for the current selection it is not easy to compare the modes of travel for different origin-destination pairs. While the JTW Visualiser shares the abstract representation of trips with our approach, its focus on binary links between suburbs makes it not well suited for analysing trip chains. Another publicly available interactive data visualisation facility is offered by the Victorian Integrated Survey of Travel \& Activity (Department of Economic Development, Jobs, Transport and Resources 2016) which allows users to explore Melbourne's JTW information by region (inner, middle, and outer) and mode of transport. JTW data is represented by interactive bar and pie charts. While this visualisation method allows users to compare mode choice for JTW by region it only shows summary statistics. It does not provide information on the complexity of trip chains and about which modes are used for which legs of the JTW. Both aspects are addressed by our proposed visualisation.

From a more general perspective, this work shares certain similarities with flow maps. These flow maps have long been used in cartography to represent movements of objects from one location to another. A well-known example of such a flow map was drawn in 1861 by Charles Joseph Minard to visualise Napoleon's Russian campaign of 1812 (Tufte 2001). In recent years, different flow map layout approaches (Phan et al. 2005; Verbeek et al. 2011) have been developed. However, flow maps show the flow between a single source and several destinations and consequently resemble a tree structure, where flow can split into distinct branches but not rejoin. As such flow maps are limited for the purpose of analysing trip chaining as passengers can arrive at a certain location from different points of origins. Alternatively, Sankey diagrams (Riehmann et al. 2005) are another way to visualise quantities of flow. Sankey diagrams have traditionally been used to visualise energy, gas, heat, or water distribution and flow or cost transfers between 
processes. Recently they have also been adopted to other domains and applications (Rosvall and Bergstrom 2010; Wongsuphasawat and Gotz 2012; Perer and Wang 2014). In contrast to flow maps, Sankey diagrams not only visualise the splitting but also the merging of flows and thus can be used to represent directed weighted graphs. Thus they would be more appropriate for our purposes. However, like flow maps, Sankey diagrams do not represent the relation between incoming and outgoing flow at a single node, an issue we address with our proposed visualisation.

Table 2 Comparison between commonly used representations for depicting information about trips or mode choice Visualisation technique

Description

Used by, e.g.,

\section{Tables}

\begin{tabular}{lcc}
\hline Chain type & frequency & \% \\
\hline Home-Work & 2,120 & 22 \\
Home-School & 1,590 & 19 \\
Home-School-Work & 378 & 3.7 \\
Home-Park-Work & 201 & 2 \\
Home-Shop-Work & 1,189 & 12 \\
\hline
\end{tabular}

Tabular representations to, e.g., list frequencies of different trip chains.
Strathman et al. (1994) and Primerano et al. (2008) to depict the frequency of various trips chains.

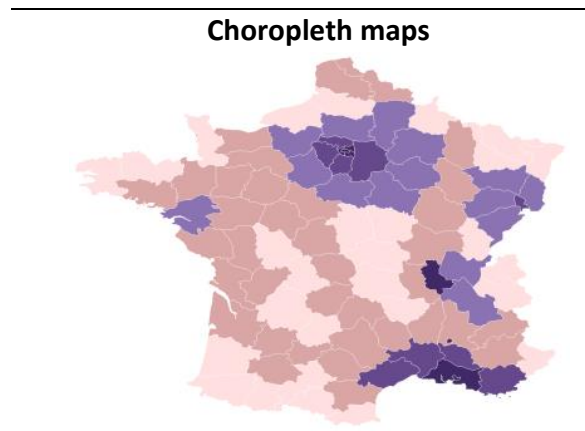

Choropleth maps shade areas in proportion to a certain variable, e.g., public transport use.
Leveson (2013) to visualise census data of England and Wales from 2011.

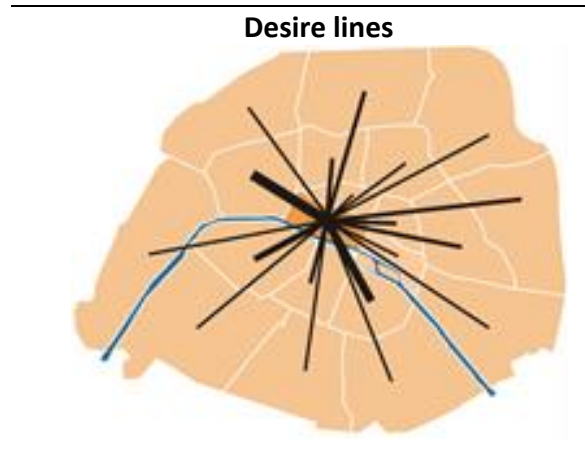

Desire lines indicate the magnitude of traffic between regions, superimposed over a map.
Xu and Milthorpe (2010) to represent journey to work data from Sydney, AU from 1981 to 2006.

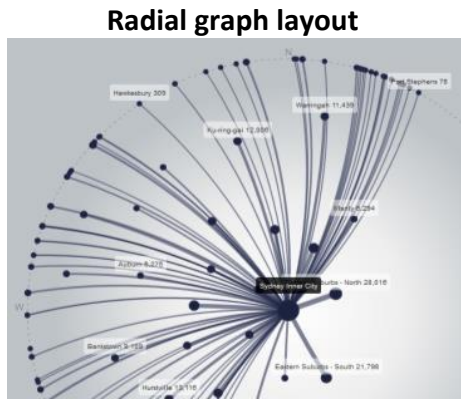

Radial graph layout showing the outgoing or incoming traffic between a certain region of interest and other regions. the JTW Visualiser of the Bureau of Transport Statistics of New South Wales from 2011 to show JTW flows between districts (accessible online: Bureau of Transport Statistics) and Sun et al. (2016) to visualise passenger flow between subway stations. 


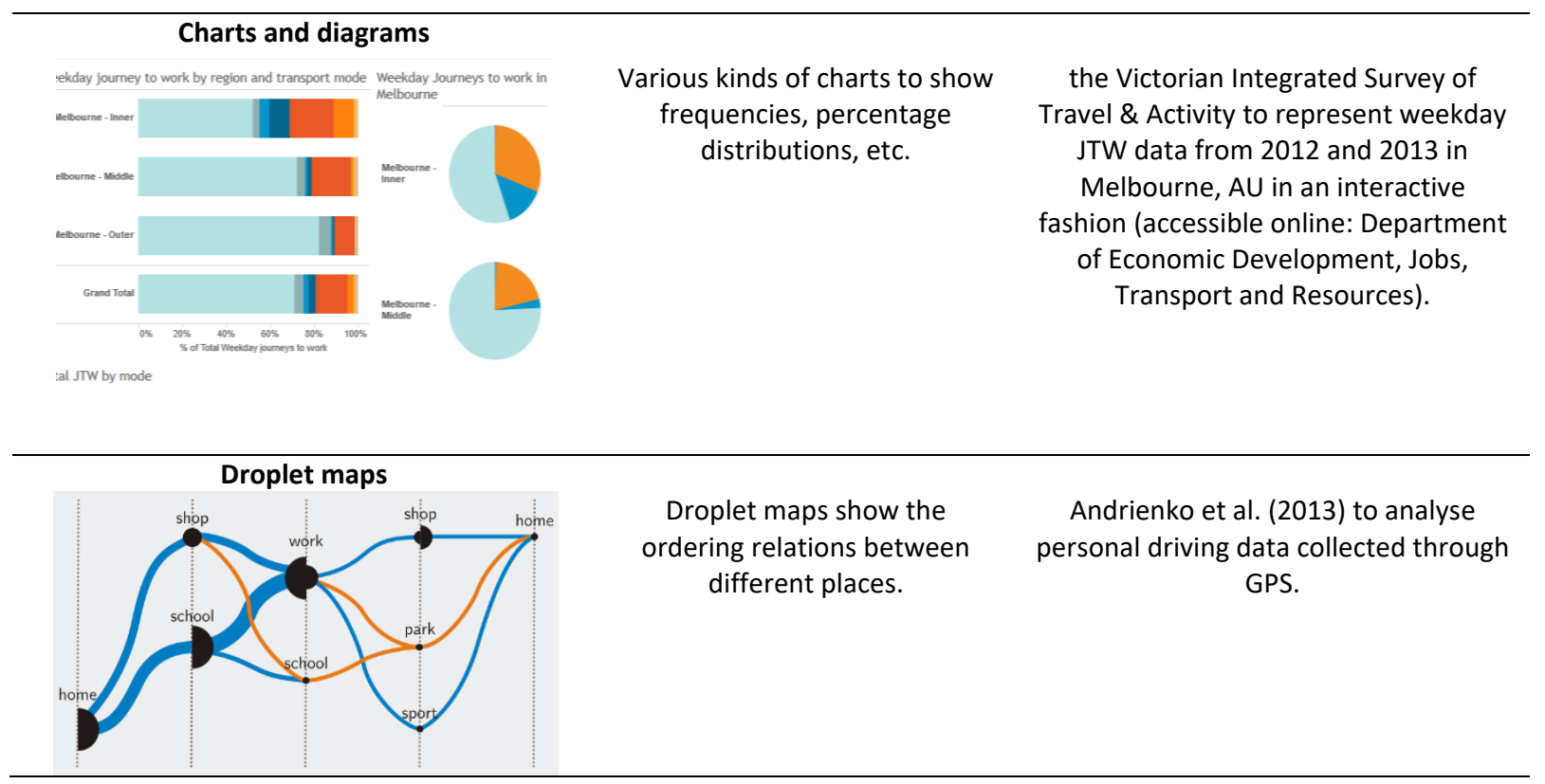

Perhaps the approach most similar to ours is the use of droplet maps as discussed in Andrienko et al. (2013). Droplet maps show the different locations along parallel vertical axes connected by lines that convey the magnitude of flow between the places. These maps allow the analysis of drivers' trips in order to see temporal or ordering relations between different places (e.g., home, work, or shopping places). However, it does not distinguish between different modes of travel and similar to Sankey diagrams the relation between incoming and outgoing flow is not deducible.

Table 2 visually compares commonly used representation techniques in the context of trip chaining and multi-modal travel analysis. In summary, we can say that many of these visualisations focus on representing summary statistics or concentrate on depicting the overall traffic between areas. In general, these visualisation techniques are thus not well suited for representing trip chaining and travel mode choice simultaneously.

In contrast to existing techniques, this paper presents a visualisation technique aimed at analysing trip chaining data and which overcomes shortcomings of existing approaches when it comes to displaying complex multi-modal trips (or trip chains). It makes use of node-link diagrams to graphically show how stops within a trip are connected and which modes of transport are used for the various legs of a journey. Such graphs can, for example, be of use for city planners as they show detailed information about travel data in a single drawing.

\section{Visualisation Approach}

Our visualisation technique provides an aggregated view of the trip scheduling behaviour of people by constructing a directed weighted graph from HTS data and then visualising this graph using node-link diagrams to show how people concatenate various activities (or modes of 
transport) on their journey toward a destination (e.g., journey to work). Each node corresponds to a stop that people make, either to change the mode of transport or to engage in an activity (e.g., shopping). It is important to note that nodes do not correspond to geographical locations or physical facilities. In this paper the term 'node' refers particularly to the types of facilities provided. For example, all different shops visited during the first stop on a trip will be represented by the same node, although in reality they might be different shops at different locations. Nodes with multiple incoming and outgoing edges are split into sub-nodes to convey the sequential relation between the arriving and departing traffic flows. Edges show the means of transport people use to travel from one stop to another. The volume of traffic (weights) is conveyed through the width of the edge and the size of the nodes.

\subsection{Algorithm}

Figure 1 provides an overview of the principal steps involved in creating an aggregated tripscheduling graph. In brief, HTS data is first filtered according to user-definable criteria (e.g., weekday, origin) and converted into a graph structure which is then laid out in a left-to-right fashion. Subsequently, nodes with more than one incoming and more than one outgoing edge are split and edges are merged to reduce visual clutter later on. In the last step, the graph is visualised. In the following the different stages are discussed in detail.

For the purpose of exposition we focus on the JTW. As mentioned earlier, however, the algorithm can be applied to other types of journeys such as journey to school or journey to home as well. In the following, we assume that we have an input database (e.g., HTS dataset) that contains a record for each trip taken by a person in a household, where a trip can contain multiple stops. In this discussion a stop is defined as a change in mode or purpose.

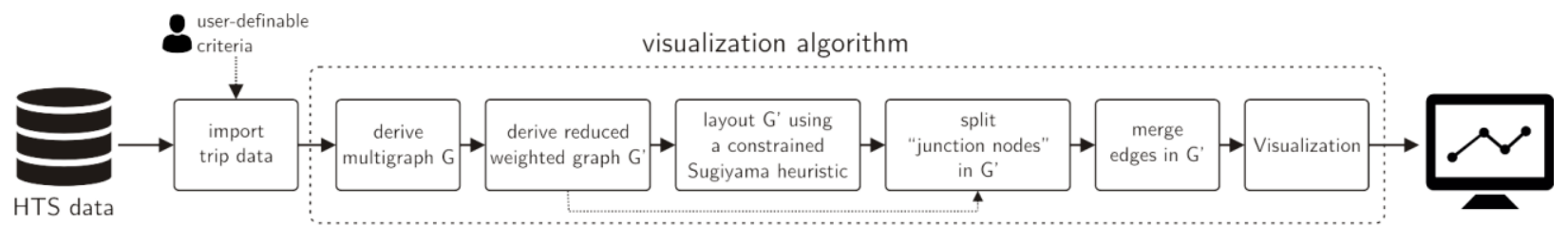

Fig 1 Overview of the principal steps of visualisation algorithm

Step 1: The process starts by extracting all stops from the input database which belong to a trip (or trip chain) originating at the respondent's home and ending at the respondent's workplace and which match certain criteria (e.g., only trips conducted on a weekday or only trips originating in a certain neighbourhood). For each trip segment, the type of the origin (e.g., accommodation, transport place), the type of the destination, the stop number, the mode of travel (e.g., walking, public bus), and the ID of the trip the segment belongs to are retrieved from the database. For all except the last trip segment of a trip, the destination of one trip segment is the origin of the next segment. 


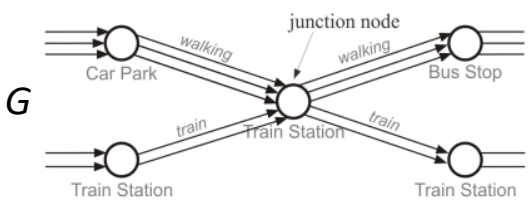

(a)

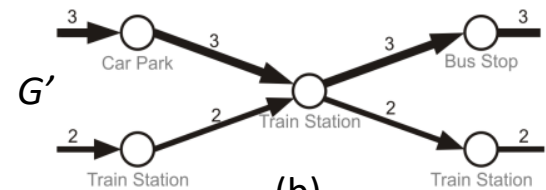

(b)

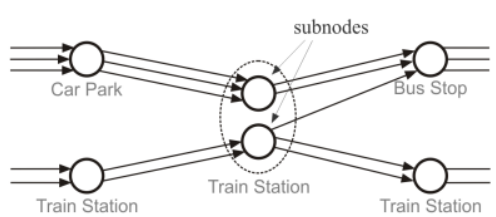

(c)

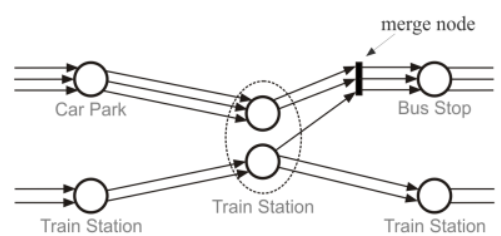

(e)

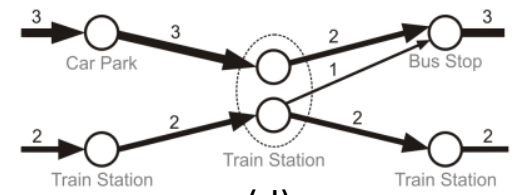

(d)

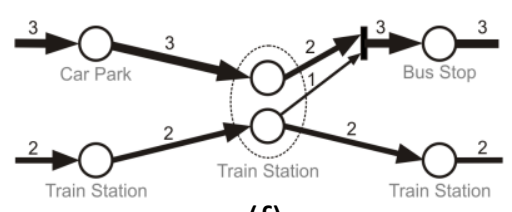

(f)

Fig 2 Splitting of nodes to convey the sequential relation of incoming and outgoing traffic flow. a) initial graph derived by extracting trip segments from a household travel survey, b) reduced graph obtained by replacing parallel edges with a single weighted edge, c) and d) graph and reduced graph after node-splitting to counteract ambiguities which arise due to 'junction nodes', e) and f) graph and reduced graph after merging edges that lead to the same node.

Step 2: The information gathered during Step 1 is used to derive a directed acyclic multigraph, formally $G=(N, E)$ where $N$ is a set of weighted nodes and $E$ is a multiset of directed edges, i.e., multiple edges between the same two nodes are permitted. Nodes represent the various types of places visited during a trip. To be more precise, $N$ is partitioned into $n+l$ subsets

$$
N=N_{0} \cup N_{1} \cup \cdots \cup N_{n}, \quad N_{i} \cap N_{j}=\varnothing, i \neq j
$$

with $n$ being equal to the number of trip segments of the longest trip. The nodes in each subset $N_{i}$, except $N_{0}$, represent the types of the destination places of the $i$-th trip segment. Note, that $N_{o}$ as well as $N_{n}$ contain only a single node, as all trips have the same origin and destination type in common, i.e., the respondents home and workplace. A specific type of place can only appear at most once in each $N i$. The weight of a node is given by the number of people who visited the associated type of stop at some point during a trip. For example, if three people stopped at a bus station after the second trip segment, then the node "bus station" in $N_{2}$ has a weight of three. Edges

$$
E \rightarrow N \times N=\left\{(u, v) \mid u \in N_{i}, v \in N_{j}, j=i+1\right\}
$$

depict the trip segments, pointing from the origin $u$ to the destination $v$ of the trip segment. Each edge is further associated with the trip ID the segment belongs to, the stop number, and the travel mode. Figure 2a shows an example how a graph may look like after this step.

Step 3: In this step, a reduced graph $G^{\prime}=\left(N, E^{\prime}\right)$ is derived from $G$ by replacing parallel edges (i.e., edges between the same two nodes) with a single weighted edge, with the edge's weight being equal to the number of parallel edges (Figure 2b). Each weighted edge $e$ in $E^{\prime}$ also maintains a list of the individual edges which are aggregated by $e$. This information will be used for colouring the edges later in the process (see Section 3.2). $G^{\prime}$ will be used for visualisation purposes, whereas calculations on the graph structure itself are performed on the more detailed graph $G$. 
Step 4: Once $G^{\prime}$ has been derived we obtain a two-dimensional embedding of $G^{\prime}$ by using the layout algorithm of Sugiyama (Sugiyama et al. 1981) - a graph drawing algorithm which is well suited for directed acyclic graphs, as it is the case in our setting. Moreover, Sugiyama's heuristic addresses several aesthetic criteria for drawing graphs, among others, minimization of edge crossings, uniform distribution of nodes, and uniform direction of edges (Healy 2013) and thus produces graph layouts which enhance readability. The Sugiyama heuristic arranges nodes in layers, generally along horizontal lines, with edges going from top to bottom but for our purposes we arrange nodes in columns with edges proceeding from left to right. Secondly, as nodes represent the stops made during a trip we want to ensure that all stops at a particular stage of a trip are not scattered over different layers but are instead located in the same layer to increase the clarity of the graph. Therefore, nodes are preassigned to layers, that is, all nodes of a subset $N_{i}$ are confined to the $i$-th layer.

Step 5: After the layout of $G^{\prime}$ has been determined some ambiguities need to be resolved which arise due to people arriving at a stop from different locations and leaving for different places. Consider, for example, the case depicted in Figure 2a. People are arriving at the train station (at the centre of the graph) either by train from another train station or by walking from a car park and then travel onwards with another train or on foot. From this representation, however, it is not clear how the individual stages are chained together as it is not possible to discern how the incoming and outgoing edges are related to each other. For example, one could get the impression that somebody was walking to the train station and then continued walking although this was not really the case. To prevent such misinterpretations, nodes with more than one incoming and more than one outgoing edge in $G^{\prime}$ (called junction nodes henceforth) are split into several nodes and incident edges are rerouted as follows. Let $n \in N$ be a junction node and let $m$ be the number of incoming edges of $n$ in $G^{\prime}$ then $n$ is split into $m$ sub-nodes $n_{s_{1}}, n_{s_{2}}, \ldots, n_{s_{m}}$. Let $I(n)$ further be the set of incoming edges connecting nodes $n_{i_{1}}, n_{i_{2}}, \ldots, n_{i_{m}}$ with $n$ in $G$ and $O(n)$ be the set of outgoing edges of $n$ in $G$. At this point it should be emphasized that the splitting itself is performed in the underlying graph $G$ as the rerouting of an outgoing edge requires knowledge of its preceding edge leading to $n$. An incoming edge $e=\left(n_{i_{k}}, n\right) \in I(n), 1 \leq k \leq m$ is then rerouted to $\left(n_{i_{k}}, n_{s_{k}}\right)$ and an outgoing edge $e=\left(n, n_{o}\right) \in O(n)$ with preceding edge $f=\left(n_{i_{k}}, n\right)$, that is $f_{\text {stopNr }}=e_{\text {stopNr }}-1$ and $f_{\text {tripID }}=e_{\text {tripID }}$, is rerouted to $\left(n_{s_{k}}, n_{o}\right)$. The weights of the newly created sub-nodes are set to the number of incoming edges after rerouting. The resulting graph is depicted in Figure 2c. Note that the splitting is performed after layouting to ensure that the subnodes of a junction node are placed close to each other (the Sugiyama heuristic, however, attempts to distribute nodes uniformly and may even place associated sub-nodes apart from each other). Hence, sub-nodes are vertically centred around the position of their respective junction node in $G^{\prime}$ with the vertical order of the sub-nodes chosen in such a way to minimise edge crossings of incident edges (Figure $2 \mathrm{~d}$ ).

Step 6: In this step, rerouted outgoing edges starting at different sub-nodes but leading to the same end node are bundled at a merge node as shown in Figure 2e. This is done to avoid cluttering the resulting visualisation with multiple edges running alongside each other, especially 
if the end node is located far away (cf. Pupyrev et al. 2011). More precisely, let $\widetilde{E}$ be the set of outgoing edges which connect different sub-nodes $n_{s}$ of a junction node with a specific adjacent node $n_{o}$ then each $\tilde{e}=\left(n_{s_{k}}, n_{o}\right) \in \widetilde{E}, 1 \leq k \leq m$ is rerouted to $\left(n_{s_{k}}, n_{M}\right)$, where $n_{M}$ is the new merge node. Furthermore, a new edge between $n_{M}$ and $n_{o}$ inheriting all attributes of $\tilde{\boldsymbol{e}}$ (e.g., mode of transport) is created. Finally, edges in $G^{\prime}$ are updated accordingly to reflect the changes made to $G$ (Figure $2 \mathrm{f}$ ).

Step 7: The graph resulting from Step 6 is visualised as described in the next section.

\subsection{Visual Representation}

Figure 3 shows how the developed visualisation technique represents multi-modal travel behaviour. The figure is based on 478 trips. The resulting graphs are to be read from left to right with the node in the first column representing the origin of the trip (or trip chain), the nodes in the second column representing all different types of stops people encountered at their first stop toward their destination, the nodes in the third column showing all different types of places when stopping for a second time and so forth.

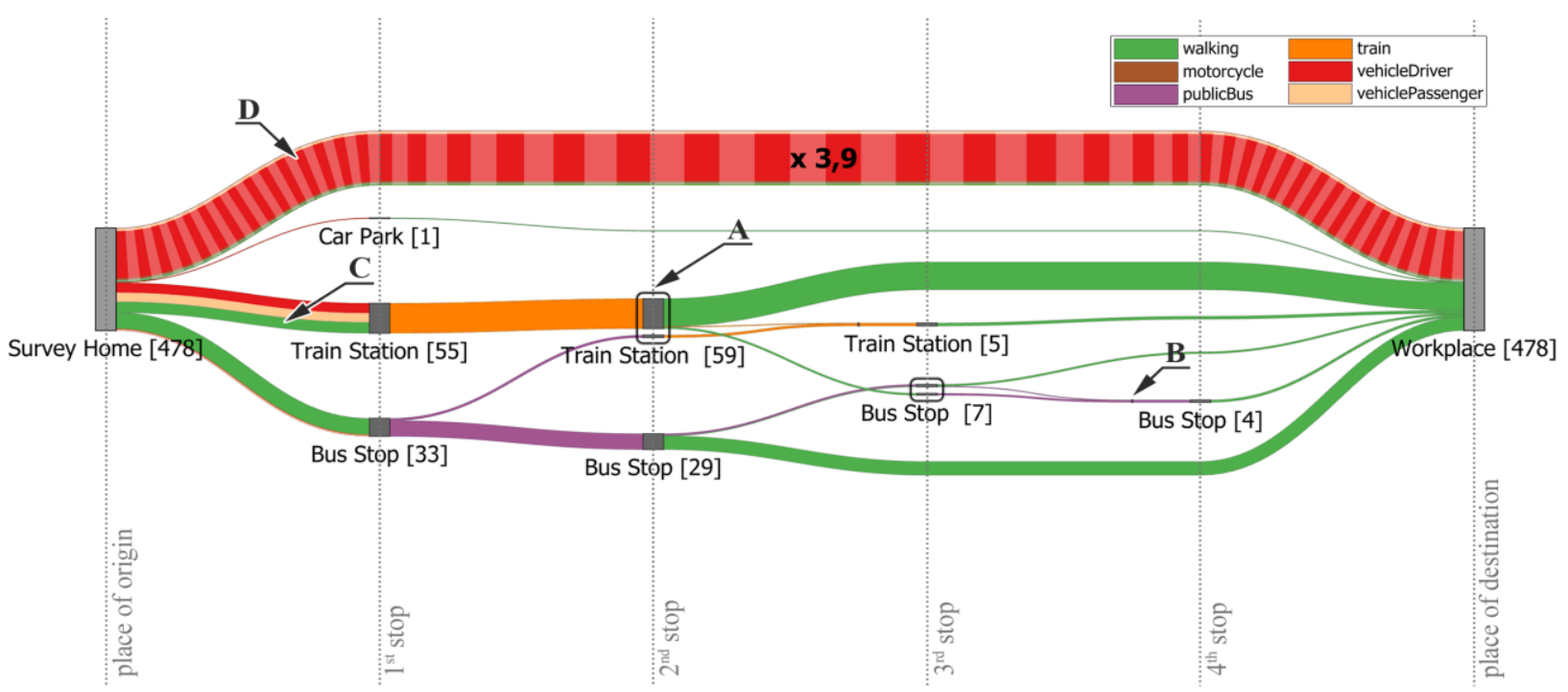

Fig 3 Graphical elements of the visualisation. The size and thickness of nodes and edges reflect the number of people. A) a junction node split into several sub-nodes to visualise how the previous stop affects the onward journey, B) edges originating at the same 'junction node' and sharing the same destination are merged to reduce edge clutter, C) the colouring of edges reflects the percentage share of different modes of transport, D) edges whose size have been limited are visually differentiated with a stripe pattern. The label of the edge provides an indicator of the actual width.

Each node has a label which shows the type of the place and the number of people who stopped there. The size and thickness of nodes and edges correspond to the number of people. Sub-nodes due to the splitting of a junction node are surrounded by a grey border to visually indicate their grouping (see Figure 3, Label A). Edges originating at the same 'junction node' and sharing the 
same destination are merged to reduce edge clutter (Figure 3, Label B). Merge nodes are rendered using a black vertical line to highlight that edges are merged at that point into a single edge and are not running alongside each other.

The algorithm can be easily adapted to handle different shapes for nodes such as circles or rectangles. However, depending on the shape the edge routing may need to be slightly adjusted to reduce overlappings in the proximity of a node. In this paper, we will restrict the discussion to rectangles. The height of the rectangle is proportional to the weight of the node (i.e., number of people passing through a place). Edges are drawn using piecewise cubic Bezier curves (edges returned by the Sugiyama heuristic can consist of multiple segments to prevent edge-node overlaps) with the width of the curve being linearly proportional to the edge weight. In case of rectangular nodes, the control points of a curve are set in such a way that the curve is entering and leaving a node horizontally. The vertical order of the outgoing edges corresponds to the vertical order of the positions of their respective end nodes to circumvent edge crossings. Incoming edges at the target are ordered in similar fashion as are edges converging at a merge node. As the outgoing flow matches the incoming flow at each node (the exception being the start and target location) the edges sum to the same height.

As all edges are pointing from the left to the right, we follow the recommendation of Holten and van Wijk (2009b) and omit arrowheads as an indicator of direction. Their user study has shown that arrowheads should be avoided whenever possible as user performance is quite low with them, probably due to occlusion and visual clutter caused by the arrowheads. Edges are rendered in order of decreasing width, i.e., thinner edges are rendered on top of thicker edges such that they lie over the thicker edges where they cross. This way occlusions of thinner edges by thicker edges are reduced. We also make use of alpha blending as suggested by Holten and van Wijk (2009a) to emphasise individual edges in areas with a high density of edges. In addition, edges are colour-coded to reflect the travel mode. For that purpose, we used an established colour scheme for qualitative data from ColorBrewer (Harrower and Brewer 2003). If different modes of transport have been used to reach a destination from the same origin, the curve is divided into sections with each section representing one mode of transport. The width of a section is proportional to the percentage share of the transport mode. For example, the stretch labelled $C$ in Figure 3 has been covered in approximately equal shares by driving, as passenger in another vehicle, or by walking.

As nodes and edges are scaled in relation to the number of people, popular routes are visually accentuated. Nevertheless, the scaling of edges and nodes can be challenging due to possible large variations in traffic volumes, for example, when a few trips (or parts thereof) are being taken by a disproportionately large number of people (such as the direct home-to-work trip). Using linear scaling with a scaling factor that scales down the width of such dominant edges to a reasonable size would cause the other less popular edges to be too thin to remain readable. Using a larger scaling factor, on the other hand, would lead to some very thick edges which would occlude large parts of the graph. On this account, we have chosen to impose an upper limit on the edge widths. Edges that are affected by this limit are visually distinguished with a stripe pattern as illustrated in Figure 3 (Label D). The multiplier on the edge is displayed to provide an 
indicator of the actual width. Logarithmic scaling would have been another alternative to compress the large range of values. However, it may make it more difficult to visually assess the differences in traffic volume. Moreover, if logarithmic scaling is used, the sum of the edge widths of the incoming edges will, in general, not be equal to the sum of the edge widths of the outgoing edges at a node. This can give the observer the false impression that the number of people changes at a node or merge node.

\section{Case Study Brisbane}

The city of Brisbane, Queensland's capital, serves as a case study to illustrate our approach. Brisbane is located within the SEQ region of the state. Brisbane, comprising 189 suburbs, has a population of about 1.1 million as of 2009 (Queensland Government, 2010). The TransLink Division of Queensland Department of Transport and Main Roads delivers transit throughout SEQ, including Brisbane City, via operator contracts. The SEQ region includes 23 transit zones of which the City of Brisbane encompasses the five innermost zones (Figure 4). This study focuses on the travel behaviour of residents living in inner Brisbane, which comprises TransLink's travel zones 1 to 3 .
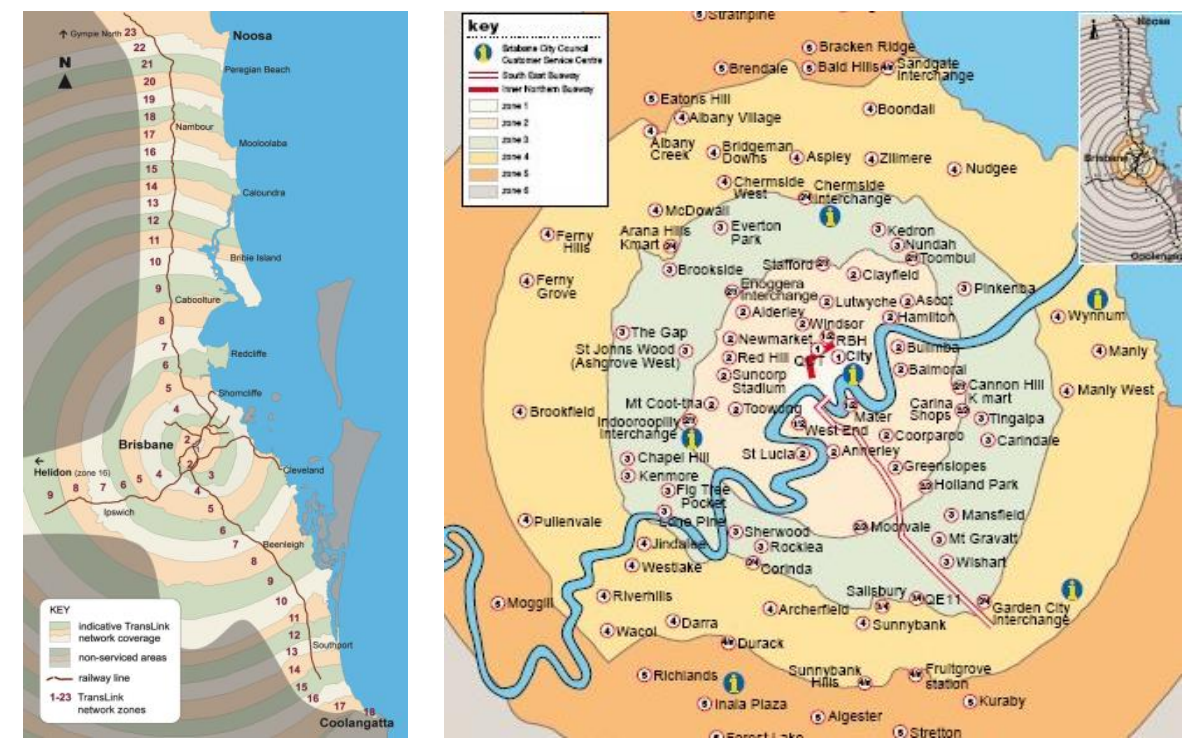

Fig 4 Left: TransLink's 23 travel zones of the SEQ area. Right: Inner areas of Brisbane City (zones 1 to 3). Source: https://translink.com.au

\subsection{Study Area and Data}

The SEQTS09 data (Department of Transport and Main Roads, 2009) are utilised to demonstrate the applicability of our approach for trip chain and multi-modal travel analysis. The SEQTSO9 database contains information about the day-to-day travel behaviour of persons living in approximately 10,000 randomly sampled private residential households within the Brisbane Statistical Division, the Gold Coast City Council, and the Sunshine Coast Regional Council area. The data were collected during a ten-week period from late April to late June in 2009 using self- 
completion questionnaires. Each household was assigned a specific day for which to fill out the questionnaire.

Table 3 Excerpt from the trip table of the SEQTS09 database for two persons. ORIGPLACE2 and DESTPLACE2 represent the type of place of the origin and destination. TIMEMODE indicates the mode with the longest travel time for a trip. Places as well as transport modes are number coded in the database.

\begin{tabular}{|c|c|c|c|c|c|c|c|}
\hline PERSID & TRIPID & TRIPNR & TRIPSTAGES & ORIGPLACE2 & DESTPLACE2 & TIMEMODE & $\ldots$ \\
\hline Y09H040119P01 & Y09H040119P01T01 & 1 & 1 & 201 & 504 & 1 & $\ldots$ \\
\hline Y09H040119P01 & Y09H040119P01T02 & 2 & 1 & 504 & 508 & 1 & $\ldots$ \\
\hline Y09H040119P01 & Ү09Н040119Р01Т03 & 3 & 1 & 508 & 301 & 1 & $\ldots$ \\
\hline ҮО9Н040119Р01 & Ү09Н040119Р01Т04 & 4 & 1 & 301 & 201 & 1 & $\ldots$ \\
\hline Ү09Н020138Р02 & Ү09Н020138Р02Т01 & 1 & 3 & 201 & 301 & 7 & $\ldots$ \\
\hline Ү09Н020138Р02 & Ү09Н020138Р02Т02 & 2 & 3 & 301 & 201 & 7 & $\ldots$ \\
\hline Ү09Н020138Р02 & Ү09Н020138Р02Т03 & 3 & 1 & 201 & 103 & 1 & $\ldots$ \\
\hline Ү09Н020138Р02 & Ү09H020138Р02Т04 & 4 & 1 & 103 & 201 & 1 & $\ldots$ \\
\hline$\ldots$ & $\ldots$ & $\ldots$ & $\ldots$ & $\ldots$ & $\ldots$ & $\ldots$ & $\ldots$ \\
\hline
\end{tabular}

Table 4 Excerpt from the stops table of the SEQTS09 database showing the stages for the two 3-stage trips from Table 3. MAINMODE indicates the mode of transport.

\begin{tabular}{|c|c|c|c|c|c|c|}
\hline Ү09Н020138Р02Т01 & Y09H020138P02S01 & 1 & 201 & 103 & 1 & $\ldots$ \\
\hline Ү09Н020138Р02Т01 & Y09H020138P02SO2 & 2 & 103 & 103 & 7 & $\ldots$ \\
\hline Ү09Н020138Р02Т01 & Y09H020138P02S03 & 3 & 103 & 301 & 4 & $\ldots$ \\
\hline Ү09Н020138Р02Т02 & Y09H020138P02S04 & 4 & 301 & 103 & 4 & $\ldots$ \\
\hline Ү09Н020138Р02Т02 & Y09H020138P02S05 & 5 & 103 & 103 & 7 & $\ldots$ \\
\hline Ү09Н020138Р02Т02 & Y09H020138P02S06 & 6 & 103 & 201 & 1 & $\ldots$ \\
\hline$\ldots$ & $\ldots$ & $\ldots$ & $\ldots$ & $\ldots$ & $\ldots$ & $\ldots$ \\
\hline
\end{tabular}

The dataset contains detailed information for each trip taken by one person of a household. A trip, as stored in the database, represents a one-way travel from an origin to a destination for a single purpose but may involve several modes of transport (stages). For each stage, several features such as start-time, type of the origin and destination, and mode of transport are recorded. All trips conducted by a single person over a day are numbered in chronological order. Table 3 and Table 4 show small excerpts from the dataset for two people. For example, the person with the ID Y09H040119P01 undertakes 4 trips with a car (TIMEMODE=1) on a single day with each trip consisting only of one stage (no change of transport). However, the person makes two stops at educational institutions (504 and 508) on the way from home (201) to work (301). In this case, the JTW thus consists of three trips. In contrast, person Y09H020138P02 does not stop on its way to work to pursue some other purpose but needs to make use of three modes of transport (TRIPSTAGES $=3$ ). First, the person drives (MAINMODE $=1$ ) to a train station (103) then takes the train to another train station before walking (MAINMODE $=4$ ) the rest of the way to the workplace. After work, the person returns back home using the same way.

Based on household trip data we derived trip chains from home to work. In addition, we assigned each household its related public transport zone ( 1 to 3 ) based on its geographic area, indicated by Statistical Area Level 1 (SA1) codes, stored in the SEQTS09 database. Some SA1 zones are, however, relatively large and may intersect more than one public transport zone. In that case, the public transport zone covering most of the area of that SA1 zone was used as the public transport zone for the entire SA1 area. 


\subsection{Results}

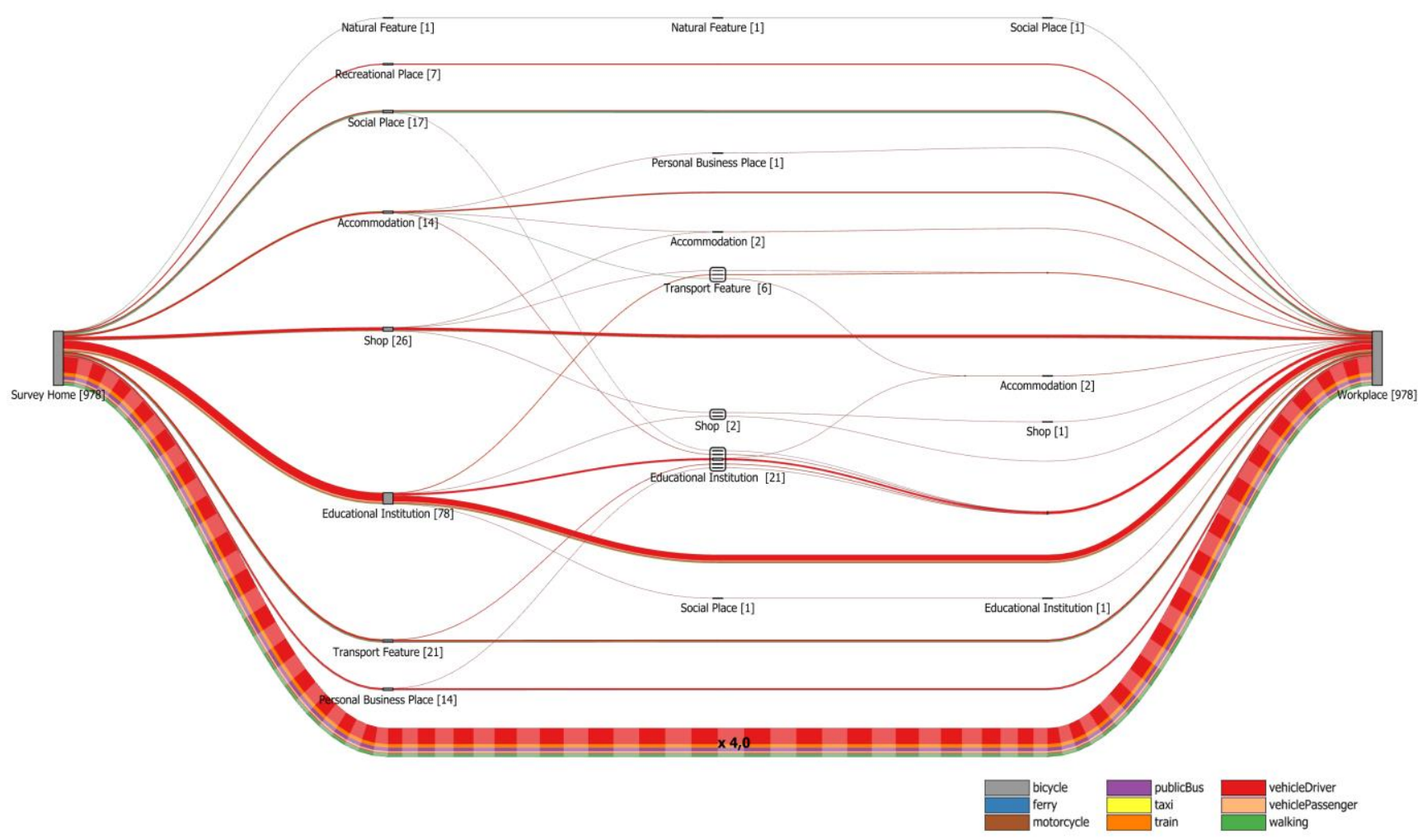

Fig 5 JTW trip chains undertaken by residents in inner Brisbane (zones 1 to 3, based on 978 journeys)

The results presented in this section make use of the SEQTSO9 dataset. To begin with, Figure 5 provides an overall view of trip chains from residents living in inner Brisbane (zones 1 to 3 ) during weekdays on their JTW. Each intermediate node reflects a category of location (indicated by the label below each node) at which people stopped during their work commute. In this example we used the course classification provided by the SEQTS09 dataset which distinguishes between ten different types of locations (e.g., educational institution, shop, accommodation). The numbers in brackets indicate how many people make the stop. Please note that each trip (= edge between two stops) represented in this graph may itself consist of multiple stages travelled by different modes of transport, i.e. be a multi-modal trip (see also Figure 6 and 7). For that reason, we adopted the longest time-mode. This means that the mode used for the longest time of the trip contributes to the colouring of the aggregated edges.

It is evident from Figure 5 that most of the people ( $82 \%$ ) did not make any additional stop on their way to work. About $50 \%$ of the people who went directly to work used their own vehicle for their journey, followed by about $25 \%$ of the people who used public transport (train and bus combined). Other transport modes such as walking or bicycle are used far less often to go directly to work. If people decide to make additional stops on their way to work then they mostly used their own vehicle. The convenience of a private vehicle possibly accounts for the relatively low use of public transport. This finding also aligns with previous studies (Strathman et al. 1994; Bhat 
1997; Hensher and Reyes 2000; Ye et al. 2007). However, none of the trip chains contains more than three intermediate stops. The second most frequent class of trip chain is that with a single intermediate stop. Of these, the most common trip chain is Home-Educational InstitutionWorkplace with people stopping at an educational institution, for instance, to drop off their children at school. The second most frequent trip chain with a single stop, Home-ShopWorkplace, includes a visit to some sort of shop, for example, to buy something to eat before going to work. This is followed by trip chains where people make a stop at some accommodation or transport feature (e.g., to pick-up a co-worker) or to visit a social place. Interestingly, in the latter case (Home-Social Place-Home), walking is a popular alternative to the private vehicle. Trip chains with two intermediate stops are few in number with people stopping at two educational institutions constituting the majority of cases. Trip chains with three stops are very uncommon.

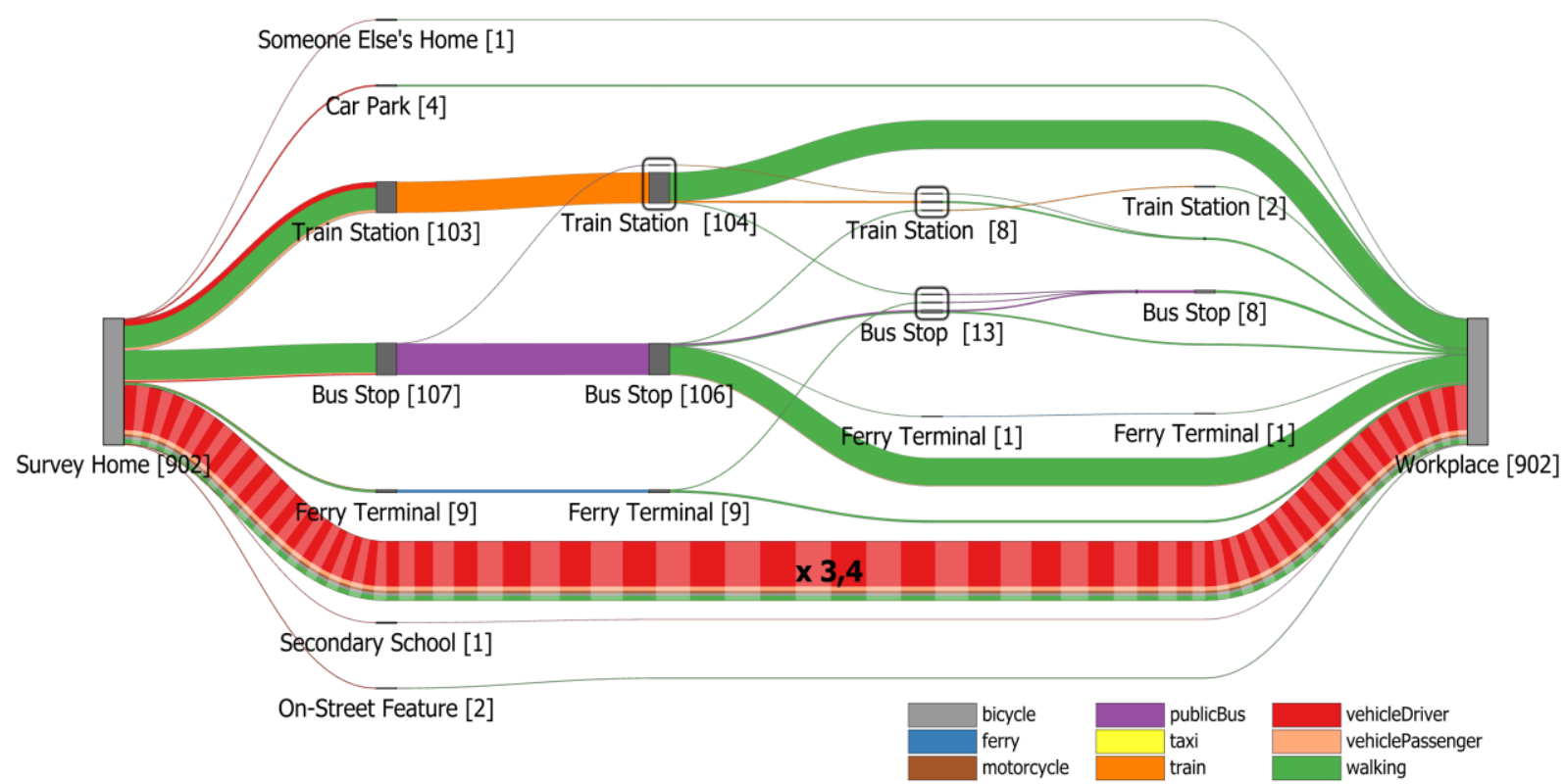

Fig 6 Multi-modal journeys of people going directly from their homes to work (zones 1 to 3)

As mentioned earlier, Figure 5 only visualises the trip chains without showing details of the intermediate stages of the trips. Figure 6 illustrates to what degree residents of inner Brisbane engage in multi-modal travel while commuting to work. It provides a detailed breakdown of multi-modal direct Home-Workplace trips (the most common trip chain according to Figure 5). Intermediate nodes in Figure 6 depict transfer locations. Labels again show the type of location but this time the more detailed classification provided by the SEQTS09 dataset was adopted to distinguish between different types of transport features (e.g., bus stop, train station). According to Figure 6, most of the surveyed households which do not pursue any activities during their JTW do not engage in multi-modal travel at all. They normally use a single mode of transport to go to work. Again, in this case residents prefer their own vehicle but cycling, walking, or travelling as vehicle passenger are also used, although to a much lesser extent. If public transport is part of the work commute then mostly only a single public transport service is used. Typically mainly either a bus or a train with ferries only playing a marginal role. When the main leg is made of a single bus or train ride, people usually walk to and from the stops. It will be noted that the 
proportion of commuters who use their own vehicles to go to a railway station is greater than that for those who go to bus stations. This may be due to the fact that train stations are located farther apart from each other than bus stations. A large proportion of people takes a single train to the destination station, while others take up two trains. Everyone completes the last leg of the journey from the station to the workplace on foot. If people go to a train station with a public bus then they do so to catch a train for their next part of the journey before walking the rest of the way.

While Figure 6 focuses on multi-modal direct home-to-work trips, Figure 7 offers an integrated view of both trip chaining behaviour and mode choice. People are making at most six intermediate stops although work commutes with more than three intermediate stops are exceptional. Two intermediate stops, on the other hand, are quite common. These trip chains mainly arise from people who rely on public transport and who walk from and to the bus and train stations. In terms of modes of transport, mainly car followed by bus and train are the preferred modes. Public ferries, for instance, only play a very minor role for the daily work commute.

\section{Discussion}

Our proposed visualisation method simultaneously represents several variables (e.g., number and types of stops) which contribute to the complexity of trip chains as well as the frequency of occurrence of trip chains, the concatenation of stops made during a trip chain, and peoples preferred modes of travel. Its purpose is making the interrelations between mode choice and trip chaining behaviour more tangible. It may help transport planners to better appreciate and identify travel demands, for example, to ensure that public transport meets the demands of the residents. Moreover, our visualisation method can clearly indicate the number of people visiting specific locations on their way to work (or between any other two locations). The complexity of trip chaining often leads to higher car dependency. Our proposed visualisation technique can, for example, assist town planners or the city council authority in planning land-use around transportation hubs. For instance, mixed-use land development and multi-purpose activity centres allow people to fulfil a variety of activities at a single location. This may encourage travellers to fulfil their desire of activities at a single location and discourage them to undertake additional trips. This, in turn, can contribute to reducing car dependency and traffic congestions. The versatility of our approach also allows for easy inclusion of additional data such as SA1 level codes. Hence, it equips researchers with the ability to zoom into the travel specifics of a certain area or to easily identify travel mode choice of a subset of the population and the dynamics behind the mode choice. Consequently, transport planners can use this information to evaluate the availability of public transport of an area along with land-use development to encourage people to reduce car travel and instead rely on other sustainable means of transportation. Besides being useful for analysing trip chaining and mode choice we can also see potential of our approach for communicating the data to policy-makers. At this point it is worth noting that although we used HTS data as input, other data sources can be used as well as long as they can be mapped to the graph structure described in Section 3.1. 


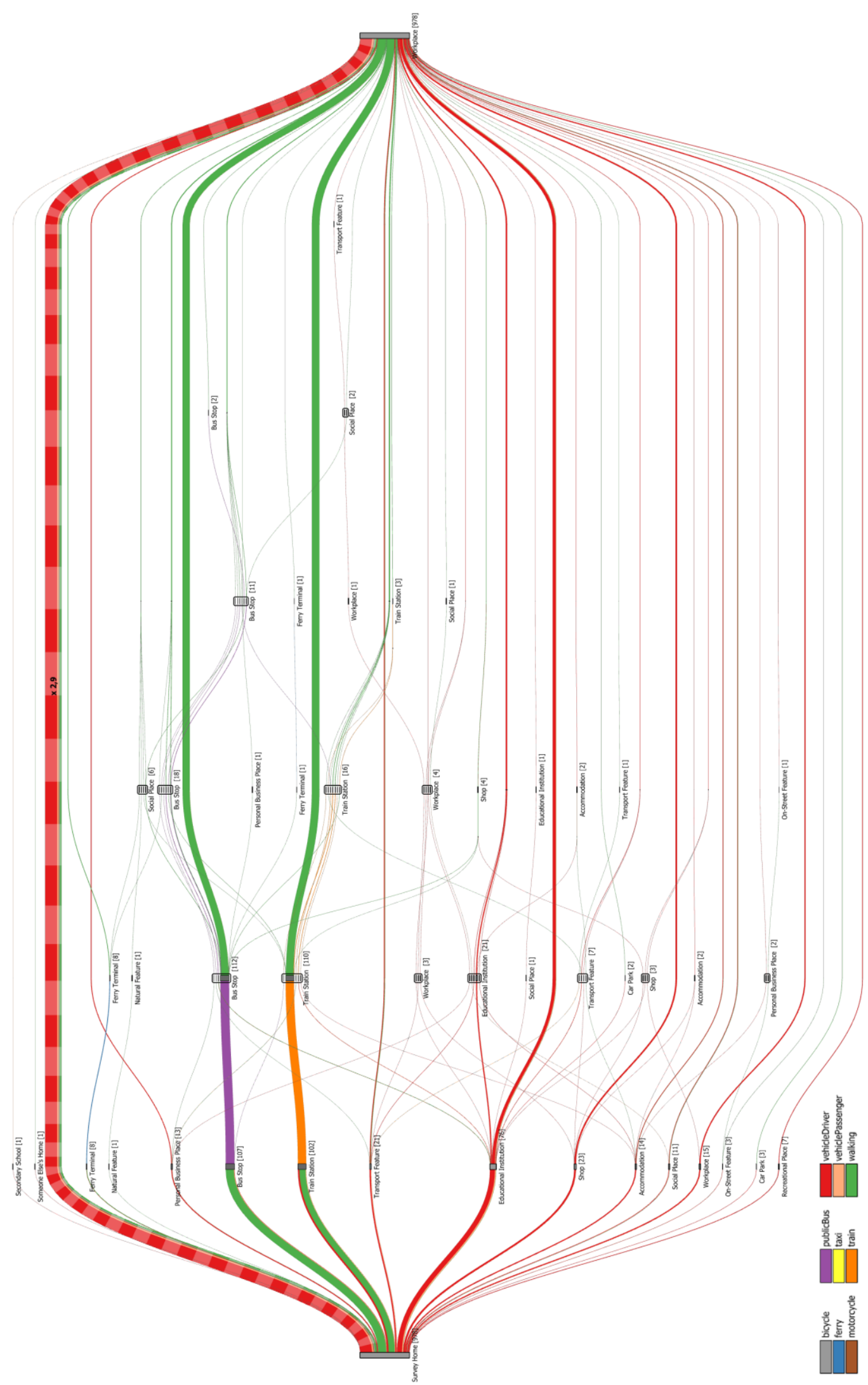

Fig 7 Integrated view of all multi-modal JTW trip chains conducted by residents of inner Brisbane on weekdays. 
For example, smart card data or data collected by electronic fare payment systems could be used to visualise passenger flow in public transportation systems.

In terms of runtime, the proposed algorithm is mainly dominated by the complexity of the Sugiyama layout algorithm when the time taken to import the data (e.g., from a database or file) is excluded. The runtime of the Sugiyama layout itself depends on the running times of the algorithms used for its individual phases. Assuming that the fastest available algorithms for each phase are used, the algorithm has a time complexity of $O\left(|N|\left|E^{\prime}\right| \log \left|E^{\prime}\right|\right)$ (see Eiglsperger et al. 2005 for an in-depth discussion). However, as the layouting is performed on the reduced graph $G^{\prime}$ which has considerable fewer edges than $G$ and because the number of nodes of $G^{\prime}$ is typically small this should not be problematic. Nevertheless, if necessary, more efficient implementations such as the one proposed by Eiglsperger et al. (2005) are available and could be used instead as well.

The second major factor influencing the overall runtime of our approach is the time complexity of the crossing reduction step which takes place after the splitting of junction nodes. This reduction is currently performed using the greedy-switch heuristic proposed by Eades and Kelly (1986), which has a time complexity which is quadratic in the number of nodes to be switched (Bastert and Matuszewski 2001). Besides, as the reduction is carried out for the sub-nodes $n_{s}$ of each junction node separately, with $\left|n_{s}\right|$ usually being small this should not be a seriously limiting factor. Moreover, if runtime is a concern then other heuristics with near-linear time complexity can be considered (see Bastert and Matuszewski (2001) for a discussion of different heuristics and their runtime and quality trade-offs). All other steps can be implemented in linear time. As such the algorithm is applicable to larger datasets such as the one used in this paper as well, especially because the runtime is not directly dependent on the number of individual trips to be processed but rather on the number of edges in the reduced graph, whereby usually $\left|E^{\prime}\right|<<|E|$.

To give some understanding of the actual timings achieved with our prototype implementation: The graph shown in Figure $5\left(|N|=21,|E|=1195,\left|E^{\prime}\right|=45\right)^{1}$ took about $344.38 \mathrm{~ms}$ to calculate of which $270.21 \mathrm{~ms}$ are spend on the Sugiyama layout and $4.55 \mathrm{~ms}$ on the node-splitting including crossing reduction. The remaining time is spread across the other stages and for setting up the necessary data structures for rendering. The timings for the graph in Figure $6(|N|=$ $\left.18,|E|=1381,\left|E^{\prime}\right|=33\right)^{1}$ are quite similar, with $336.32 \mathrm{~ms}$ in total of which the Sugiyama layout consumes $279.70 \mathrm{~ms}$ and the node-splitting $4.43 \mathrm{~ms}$. For comparison, a larger graph with $|N|=77,|E|=9405$, and $\left|E^{\prime}\right|=273$ takes about $944.74 \mathrm{~ms}$ to calculate with $488.78 \mathrm{~ms}$ and 117.33 $\mathrm{ms}$ for layouting and node splitting, respectively. All given values are averaged over 10 runs of the algorithm and were measured on an Intel Core i5-6400 2.7GHz Quad-Core CPU with 8GB RAM and are exclusive the time for data import.

\footnotetext{
${ }^{1}$ At the time of layouting. The final number of nodes and edges is slightly higher due to the introduction of sub-nodes during the node-splitting stage and of merge nodes and additional edges during the merge edges stage of the algorithm.
} 
In terms of space requirements, we maintain two graphs $-G$ and $G^{\prime}$ - in parallel, requiring $O(|N|+|E|)+O\left(|N|+\left|E^{\prime}\right|\right)$ space. Please note that the number of nodes and thus the visual complexity of the resulting graph is partly influenced by the number of types of places which are distinguished. In Figure 5, as pointed out above, we directly used the course classification of the SEQTS09 dataset which differentiates between ten types of places. Some of these places are, however, rarely visited during the work commute (e.g., recreational place or natural feature). If desired by the analyst such seldom visited places may be merged together. By doing so, edges connecting these types of places also become thicker which might make it also easier to see the modal differentiation.

One challenge in visualizing HTS data is the complexity of factors influencing the travel choices of people. A multitude of variables has been recognized to influence the travel behaviour, including individual or household characteristics (e.g., age, gender, marital status, presence of children, or number of vehicles per household) and geographical area (Hensher and Reyes 2000; Ma et al. 2014; McGuckin and Murakami 1999). While we focused on analysing JTW patterns of residents living within certain public transport zones in the above case study, these other characteristics can be used as well to generate individual graphs for certain segments of the public. For example, separate JTW graphs for males and females or individual graphs for each district in a city. For comparison purposes, these graphs could then be visualised side-by-side by using small multiples.

Similarly, there exist a number of attributes which can be used for describing and understanding trip chains and multimodal travel. Our visualisation currently represents an important subset of these attributes, such as frequency of trips, mode choice, and number of stops. However, there exist other attributes (e.g., purpose, travel time, or distance travelled) which should also be considered for inclusion. Small multiples could, for example, also be used to generate graphs based on travel time or distance. Currently it is also not apparent from the visualisation which activities people pursue at the different locations. Activities, however, play an important role in activity-based approaches to travel behaviour analysis (Xianyu 2013). For example, a commuter may not necessarily stop at a train station to catch a train but to withdraw money from an ATM. One possibility to show such information could be by colouring the nodes in proportion to the purpose of the stop. However, we refrained from doing so mainly for two reasons. 1) As we are concerned with nominal data it is important that the colours are reliably distinguishable be the human observer (cf. Silva et al. 2011). Research suggests that humans can rapidly perceive about five to ten different colours (see Ware 2004). The SEQTS09 dataset we used, however, differentiates between at least 10 purposes which would have approximately doubled the amount of colours or one and the same colour would have to be used for different categories. 2) As the nodes can be rather small the percentage share of the different activities may be hard to assess visually. Such information could, for instance, be displayed by tooltips. Tooltips may also be used to display more detailed information on demand (e.g., exact percentage shares for the different modes of transport). As part of future work we are thus considering to develop the visualisation into an interactive system which allows users to access detailed information on demand and offers them the possibility to compare multiple trip scheduling graphs using small multiples. We are also considering ways to incorporate temporal attributes into the visualisation. 
This would offer new opportunities for analysis such as investigating trip chains or mode choice with respect to commute time.

\section{Conclusions}

Research on the complex phenomena of trip chaining and travel mode choice can benefit from visualisations which complement existing tabular and statistical methods. However, our review of literature has shown that visualisations currently used for analysing trip chaining and multimodal travel are limited in the amount of simultaneously displayed variables. Most visualisations focus on representing aggregated statistics and the amount of traffic or passenger flow between pairs of regions or stations (i.e. single trips without intermediate stops). In contrast, the visualisation introduced in this paper provides an aggregated view of trips chains and mode choice at the same time by means of node-link diagrams. Several variables, including the number and type of stops (e.g., bus station, shopping mall) within trip chains, the quantity of traffic at and between stops, as well as the different modes of transport used to reach a location/destination are displayed. Moreover, our proposed technique allows to inspect the sequential relation between incoming and outgoing traffic at stops. We achieve this by splitting nodes where people arrive from more than one location and continue to different destinations into sub-nodes. This way we can resolve ambiguities which would arise in related approaches like flow maps (Phan et al. 2005) or Sankey diagrams (Riehmann et al. 2005) (see Section 2 for details), where it is not clear which part of the incoming flow continues to which subsequent node. Using data from the South East Queensland 2009 household travel survey we demonstrated how the visualisation can be used to reveal patterns in the travel behaviour of residents. While we focused on the JTW in this paper we would like to reemphasize that the algorithm is general enough to be applied to other types of journeys as well. Future work will focus on the inclusion of further variables (e.g., activities performed at stops) and on integrating the visualisation into an interactive system which allows users to compare different graphs and to access detailed information on demand.

\section{Acknowledgements}

We would like to thank the Queensland Department of Transport and Main Roads for providing the HTS data.

\section{References}

Alsnih R, Hensher DA (2005) The travel behaviour of seniors in an ageing population in Sydney: An exploratory study of trip chains and modal preferences in the greater metropolitan area of Sydney. Road and Transport Research 14 (4): 60-76. 
Andrienko G, Andrienko N, Bak P, Keim D, Wrobel S (2013) Visual analytics focusing on space. In Visual Analytics of Movement. Springer Berlin Heidelberg, 253-305. DOI:10.1007/978-3-64237583-5_7.

Bastert O, Matuszewski C (2001) Layered drawings of digraphs. In Drawing Graphs: Methods and Models, 87-120. Springer Berlin Heidelberg.

Bhat CR (1997) Work travel mode choice and number of non-work commute stops. Transportation Research B 31(1): 41-54.

Bhat CR, Koppelman FS (1999) Activity-based modeling of travel demand. In: Hall RW (ed) Handbook of Transportation science. Springer, US 23:35-61. DOI:10.1007/978-1-46155203-1_3.

Bureau of Transport Statistics: JTW Visualiser. http://visual.bts.nsw.gov.au/jtwdynamic/ (Accessed: July, 2017)

Capiler Corporation. TransCAD transportation planning software. http://www.caliper.com/TCTravelDemand.htm (Accessed: July, 2017)

Corcoran J, Chhetri P, Stimson R (2009) Using circular statistics to explore the geography of the journey to work. Papers in Regional Science 88(1): 119-132. DOI: 10.1111/j.14355957.2008.00164.x.

Currie G, Delbosc A (2011) Exploring the trip chaining behavior of public transport users in Melbourne. Transport Policy 18:201-210.

Department of Economic Development, Jobs, Transport and Resources (2016) VISTA 2012-13 Journey to work - Victorian Integrated Survey of Travel \& Activity (VISTA) https://public.tableau.com/profile/dedjtr\#!/vizhome/VISTA2012-13-Journeytowork/JTWmethodoftravel. (Accessed July, 2017)

Department of Transport and Main Roads (2009) South East Queensland Travel Survey 2009.

Eades P, Kelly D (1986) Heuristics for reducing crossings in 2-layered networks. Ars Combin. 21:89-98.

Eiglsperger M, Siebenhaller M, Kaufmann M (2005) An efficient implementation of Sugiyama's algorithm for layered graph drawing. Journal of Graph Algorithms and Applications 9(3):305-325.

Fiorenzo-Catalano S, Van Nes R, Bovy PH (2004) Choice set generation for multi-modal travel analysis. European Journal of Transport and Infrastructure Research 4(2):195-209.

Golob TF, Hensher DA (2007) The trip chaining activity of Sydney residents: A cross- section assessment by age group with a focus on seniors. Journal of Transport Geography 15:298312. DOI:10.1016/j.jtrangeo.2006.09.005. 
Habib KMN, Day N, Miller EJ (2009) An investigation of commuting trip timing and mode choice in the Greater Toronto Area: Application of a joint discrete-continuous model. Transportation Research A 43(7): 639-653. DOI: 10.1016/j.tra.2009.05.001.

Harney D, Rajoo PD (2015) Moving to tour based models in QLD, is it time? Australian Institute of Traffic Planning and Management (AITPM) National Conference, 28-31 July 2015, Brisbane, Queensland.

Harrower M, Brewer C (2003) ColorBrewer.org: An online tool for selecting colour schemes for Maps. The Cartographic Journal 40(1):27-37. The British Cartographic Society. DOI: 10.1179/000870403235002042.

Healy N (2013) Hierarchical drawing algorithms. In: Tamassia R (ed) Handbook of Graph Drawing and Visualization. Chapman and Hall/CRC.

Hensher DA, Reyes AJ (2000) Trip chaining as a barrier to the propensity to use public transport. Transportation 27(4):341-361. DOI: 10.1023/A:1005246916731.

Hensher DA (2007) Some insights into the key influences on trip chaining activity and public transport use of seniors and the elderly. International Journal of Sustainable Transportation 1(1): 53-68. DOI: 10.1080/15568310601097004.

Holten D, Van Wijk JJ (2009a) Force-directed edge bundling for graph visualization. In Proceedings of the 11th Eurographics/IEEE - VGTC Conference on Visualization (Aire-laVille, Switzerland, Switzerland), EuroVis'09, Euro graphics Association, 983-998. DOI: 10.1111/j.1467-8659.2009.01450.x.

Holten D, Van Wijk JJ (2009 b) A user study on visualizing directed edges in graphs. In Proceedings of the SIGCHI Conference on Human Factors in Computing Systems (New York, NY, USA), CHI '09, ACM, 2299-2308. DOI: 10.1145/1518701.1519054.

Islam MT, Habib KN (2012) Unraveling the relationship between trip chaining and mode choice: Evidence from a multi-week travel diary. Transportation Planning and Technology 35(4):409-426.

Leveson GT (2013) 2011 Census analysis - Method of travel to work in England and Wales Report. Tech. rep., Office for National Statistics.

Ma J, Mitchell G, Heppenstall A (2014) Daily travel behaviour in Beijing, China: An analysis of workers' trip chains, and the role of socio-demographics and urban form. Habitat International 43:263-273.

Manore MA (2007) Visualization in transportation 101. In TR News, Visualization in Transportation: Empowering innovation, Transportation Research Board of the national academes. Number 252, September-October. 
McGuckinN, Murakami E (1999) Examining trip-chaining behavior. A comparison of travel by men and women. Transportation Research Record: Journal of the Transportation Research Board 1963:79-85. http://nhts.ornl.gov/1995/Doc/Chain2.pdf. DOI: 10.3141/1693-12.

McGuckin N, Zmud J, Nakamoto Y (2005) Trip chaining trends in the U.S. - Understanding travel behaviour for policy making. Transportation Research Record: Journal of the Transportation Research Board 1917. DOI: 10.3141/1917-22.

Monteiro N, Rossetti R, Campos P, Kokkinogenis Z (2014) A framework for a multimodal transportation network: An agent-based model approach. Transportation Research Procedia 4:213-227. DOI: 10.1016/j.trpro.2014.11.017.

Nagel T, Maitan M, Duval E, Moere AV, Klerkx K, Ratti C (2014) Touching transport - a case study on visualizing metropolitan public transit on interactive tabletops. In Proceedings of the 2014 International Working Conference on Advanced Visual Interfaces (New York, NY, USA, 2014), AVI '14, ACM, pp. 281-288. DOI: 10.1145/2598153.2598180.

Omer M, Kim H, Sasaki K, Nishii K (2010) Tour based travel demand model using person trip data and its application to advanced policies. KSCE Journal of Civil Engineering 14(2):221230.DOI: 10.1007/s12205-010-0221-6.

Perer A, Wang F (2014) Frequence: Interactive mining and visualization of temporal frequent event sequences. In Proceedings of the 19th International Conference on Intelligent User Interfaces, IUI'14, ACM, 153-162. DOI: 10.1145/2557500.2557508

Phan D, Xiao L, Hanrahan P, Wino-Grad T (2005) Flow map layout. In Proceedings of the 2005 IEEE Symposium on Information Visualization, IEEE Computer Society, 219-224.

Philip M, Sreelatha T, George S (2013) Activity based travel behavioural study and mode choice modelling. International Journal of Innovative Research in Science, Engineering and Technology, 2(1), 181-190.

Primerano F, Michael APT, Pitaksringkarn L, Tisato P (2008) Defining and understanding trip chaining behavior. Transportation 35(1):55-72. DOI: 10.1007/s11116-007-9134-8

Public Transport Victoria - Journey Planner. https://www.ptv.vic.gov.au/journey (Accessed: July, 2017)

Pupyrev S, Nachmanson L, Kaufmann M (2011) Improving layered graph layouts with edge bundling. In: Graph Drawing, Brandes U, Cornelsen S.(Eds) vol. 6502 of Lecture Notes in Computer Science. Springer, Berlin Heidelberg,329-340. DOI: 10.1007/978-3-642-184697_30.

Queensland Government - Office of Economic and Statistical Research (2010) Information brief - Regional Population Growth: 2008-09. 
http://www.qgso.qld.gov.au/products/reports/pop-growth-reg-qld/reg-pop-growth-200809.pdf (Accessed: August, 2017)

Rail Europe - Rail travel planner Europe. http://www.raileurope-world.com (Accessed: July 2017)

Riehmann P, Hanfler M, Froehlich B (2005) Interactive Sankey diagrams. In Proceedings of the IEEE Symposium on Information Visualization, INFOVIS, 233-240. DOI: 10.1109/INFVIS.2005.1532152.

Rosvall M, Bergstrom T (2010) Mapping change in large networks. PLoS ONE 5:1. DOI: 10.1371/journal.pone.0008694.

Shiftan Y (1998) Practical approach to model trip chaining. Transportation Research Record 1645:17-23.

Silva S, Santos B S, Madeira J (2011) Using color in visualization: A survey. Computers \& Graphics, 35(2), 320-333.

Strathman JG, Dueker KJ, Davis JS (1994) Effects of household structure and selected travel characteristics on trip chaining. Transportation 21(1):23-45.DOI:10.1007/BF01119633.

Sugiyama K, Tagawa S, Toda M (1981) Methods for visual understanding of hierarchical system structures. IEEE Transactions on Systems, Man and Cybernetics 11(2):109-125. DOI: 10.1109/TSMC.1981.4308636.

Sun Y, Shi J, \& Schonfeld PM (2016) Identifying passenger flow characteristics and evaluating travel time reliability by visualizing AFC data: a case study of Shanghai Metro. Public Transport, 8(3), 341-363.

TransLink - Journey Planner. http://jp.translink.com.au (Accessed: July, 2017)

Tufte E (2001) The visual display of quantitative information. Graphics Press.

Verbeek K, Buchin K, Speckmann B (2011) Flow map layout via spiral trees. IEEE Transactions on Visualization and Computer Graphics 17(12), 2536-2544.

Walle SV, SteenberghenT (2006) Space and time related determinants of public transport use in trip chains. Transportation Research Part A40:151-162.

Wallace B, Barnes J, Rutherford GS (2000) Evaluating the Effect of traveler and trip characteristics on trip chaining, with implications for transportation demand management strategies. Transportation Research Record 1718:97-106.

Ware C (2004) Information visualization: Perception for design. $2^{\text {nd }}$ edition. Morgan Kaufmann. 
Wongsuphasawat K, Gotz D (2012) Exploring flow, factors, and outcomes of temporal event sequences with the outflow visualization. IEEE Transactions on Visualization and Computer Graphics 18(12): 2659-2668. DOI: 10.1109/TVCG.2012.225.

Xianyu J (2013) An exploration of the interdependencies between trip chaining behavior and travel mode choice. Procedia - Social and Behavioral Sciences 96: 1967-1975. DOI: 10.1016/j.sbspro.2013.08.222.

Xu M, Milthorpe F, Tsang K (2011) Detailed analysis of the travel patterns of rail users in Sydney. In Proceedings of the Australasian Transport Research Forum.

Xu B, Milthorpe F (2010) Analysis of journey to work travel patterns in Sydney. In Proceedings of the Australasian Transport Research Forum.

Ye X, Pendyala RM, Gottardi G (2007) An exploration of the relationship between mode choice and complexity of trip chaining patterns. Transportation Research Part B 41: 96-113. DOI: 10.1016/j.trb.2006.03.004. 